UDK: 621.316.925

DOI: https://doi.org/10.24867/12BE07Djurdjevic

\title{
KONFIGURISANJE I TESTIRANJE MIKROPROCESORSKOG RELEJA ZA ZAŠTITU ELEKTROENERGETSKIH VODOVA
}

\section{CONFIGURATION AND TESTING OF MICROPROCESSOR BASED RELAY FOR POWER LINES PROTECTION}

\author{
Milan Đurđević, Zoran Stojanović, Fakultet tehničkih nauka, Novi Sad
}

\section{Oblast - ELEKTROTEHNIKA I RAČUNARSTVO}

Kratak sadržaj - U radu su dati osvnovni principi rada relejne zaštite. Navedene su i opisane osnovne zaštite koje se koriste u štićenju električnih mreža. Kao primjer dat je jedan tip mikroprocesorsog releja i objašnjene su njegove zaštitne funkcije. Nakon detaljnog objašnjenja, praktičnim radom funkcije su ispitane odgovarajućim testnim alatom $i$ uporednom analizom povratnih informacija kako $u$ releju tako $i$ u testnom alatu izvedeni su određeni zaključci.

Ključne reči: Relejna zaštita, Mikroprocesorski relej, Elektroenergetski vod

Abstract - This document presents the basic principles of relay protection. The basic protection functions used in the protection of elecrtical networks are listed and described. One type of microprocessor relay is used as an example and its protective functions are explained. These functions are tested with an appropriate testing tool and a comparative analysis of the feedback in both the relay and the test tool, certain conclusions were obtained.

Keywords: Relay protection, Microprocessor relay, Power line

\section{UVOD}

Oblast relejne zaštite predstavlja jednu od najvažnijih oblasti elektroenergetike koja treba da pruži adekvatnu zaštitu elemenata sistema, a posredno i zaštitu rukovaoca tim elementima. Iz tih razloga je neophodno da uređaji relejne zaštite budu ispravni i pouzdani, da bi u svakom trenutku mogli da odreaguju na unaprijed definisan način. Osnovni zadatak elektroenergetskog sistema je da obezbijedi pouzdanu proizvodnju, prenos i distribuciju eleltrične energije krajnjim potrošačima. Postoji više faktora koji utiču na pouzdanost, a najvažniji od njih su:

- topologija mreže;

- način uzemljenja neutralne tačke;

- tipovi kvarova kojima je mreža izložena;

- $\quad$ korišteni sistem relejne zaštite.

Relej predstavlja uređaj koji je napravljen tako da kada se na njegove ulaze dovodi električna, mehanička ili neka druga veličina odgovarajućeg intenziteta, djeluje na unaprijed određen način.

\section{NAPOMENA:}

Ovaj rad proistekao je iz master rada čiji mentor je bio dr Zoran Stojanović, vanr. prof.
Takođe može se reći i da je to uređaj koji služi za detekciju nenormalnih pogonskih stanja djelova elektroenergetskog sistema i inicijalizaciju odgovarajućih upravljačkih akcija za obezbjeđenje normalnog pogona [1]. Pod nenormalnim pogonskim stanjima podrazumijevamo stanja sa kvarom i opasna pogonska stanja [1].

\section{ZAŠTITA ELEKTRIČNIH MREŽA}

Električne mreže kao dio elektroenergetskog sistema služe za prenos električne energije od izvora do potrošačkih područja, za međusobno povezivanje dijelova elektroenergetskog sistema ili velikih sistema u jedinstven sistem, te za raspodjelu električne energije unutar potrošačkih područja, sve do svakog pojedinačnog potrošača [2].

Prema naponskim nivoima mogu se podijeliti na:

- $\quad$ Niskonaponske mreže - NN napona 400/230 V, $\mathrm{u}$ industriji i $500 \mathrm{~V}$;

- Srednjenaponske mreže - SN napona $6 \mathrm{kV} \mathrm{u}$ industriji i 10,20 i $35 \mathrm{kV}$ za distribuciju električne energije;

- Visokonaponske mreže - VN napona 110, 220 i $400 \mathrm{kV}$;

- Mreže vrlo visokih napona - VVN 500, 750 i $1000 \mathrm{kV}$.

$\mathrm{U}$ zavisnosti od izvedbe, mogu biti nadzemne (dalekovodi) i podzemne (kablovi) [2] .

Osnovna karakteristika električnih mreža jeste njihova rasprostranjenost na velikim područijima. Vodovi prolaze manje ili više nepogodnim terenima i u pogonu su izloženi mnogobrojnim vanjskim uticajima. Zbog toga su električne mreže dio elektroenergetskog sistema na kojem se pojavljuje relativno veliki broj kvarova [2].

Prema broju faza obuhvaćenih kvarom oni mogu biti:

- Tropolni i dvopolni kratki spojevi bez spoja sa zemljom;

- Tropolni, dvopolni i jednopolni kratki spojevi sa zemljom u mrežama sa efikasno uzemljenim zvjezdištem mreže;

- Zemljospojevi jedne faze u mrežama sa izolovanim ili kompenozovanim zvjezdištem.

Za zaštitu elekričnih mreža koriste se sledeće vrste zaštita [1]:

1. Prekostrujna zaštita;

2. Distantna zaštita;

3. Diferencijalna zaštita;

4. Zaštita osiguračima. 
Prekostrujna zaštita predstavlja najjednostavniju i najčešće primjenjivanu zaštitu u srednjenaponskim mrežama (10-35 kV). Primjenjuje se uspješno u mrežama sa radijalnim napajanjem. U zavisnosti od usmjerenja može biti neusmjerena i usmjerena.

Razlikujemo dva načina korištenja ove zaštite i to: sa strujno nezavisnom vremenskom karakteristikom i strujno zavisnom vremenskom karakteristikom. Prednosti prekostrujne zaštite su u njenoj jednostavnosti, sigurnosti i rezervnom djelovanju. Nedostatak je relativno sporo djelovanje kod kvarova u blizini izvora napajanja, naročito ako na radijalnom vodu ima više podstanica [2].

Mreže složenijih oblika sa višestranim napajanjem, kakve su po pravilu visokonaponske mreže za prenos električne energije, ne mogu se selektivno štititi običnim ni usmjerenim prekostrujnim relejima, ali se mogu veoma uspješno štititi pomoću distantnih releja. Pošto vrijeme djelovanja ovih releja zavisi od udaljenosti mjesta kvara, može se postići selektivno djelovanje bez obzira na oblik i uklopno stanje mreže [2].

Ova zaštita ima dva parametra za podešavanje:

1) impedansu pomoću koje se određuje domet odnosno doseg zaštite $\mathrm{i}$

2) vrijeme djelovanja koje u stvari predstavlja vrijeme kašnjenja pri djelovanju zaštite u nekom stepenu.

Kombinacijom ova dva parametra postiže se traženi kvalitet zaštite - što je kvar bliže releju, to se on brže eliminiše [1]. Prednost štićenja vodova pomoću distantne zaštite je u postizanju brzog i selektivnog isključenja kratkih spojeva, kao i u velikoj osjetljivosti zaštite. Prednost je i rezervno djelovanje u slučaju zatajenja prethodne zaštite [2]. Nedostatak distantne zaštite je postojanje zone štićene drugim stepenom sa relativno dugim vremenskim zatezanjem koje je neugodno kod primjene automatskog ponovno uključenja.

Razlikujemo dvije vrste diferencijalne zaštite: podužna i poprečna. Podužna se koristi uglavnom na relativno kratkim vodovima, dok se poprečna primjenjuje na paralelnim vodovima.

Podužna diferencijalna zaštita koristi principe diferencijalne zaštite i osim što se koristi za zaštitu generatora $i$ transformatora, može se koristiti i za zaštitu vodova, poredeći amplitudu i fazni stav struja na početku i na kraju voda. Podužna diferencijalna zaštita se obično primjenjuje za vodove dužina do $15 \mathrm{~km}$ i ovaj tip zaštite vodova predstavlja najselektivniji i praktično najbrži tip zaštite koji se može koristiti za eliminaciju kvara na vodu. Sa ovim tipom zaštite kvar se detektuje za oko 30 ms [2].

Prednosti podužne diferencijalne zaštite $u$ odnosu na ostale su to što postiže selektivnost djelovanja zaštite kod kvara na štićenom vodu bez potrebe prilagođavanja i stepenovanja sa susjednim zaštitama, veoma je brza, sigurna je u pogonu, bez dodatnih mjera postiže se istovremeno isključenje prekidača na oba kraja voda, što omogućava efikasnu primjenu brzog automatskog ponovnog uključenja. Glavni nedostatak ove zaštite jeste primjena pilot provodnika koji se mora stalno kontrolisati da eventualno nije prekinut.
Poprečna diferencijalna zaštita se primjenjuje na paralelnim vodovima. Prednost ove zaštite je u njenoj jednostavnosti, brzini djelovanja i $\mathrm{u}$ tome što nije potreban spojni vod između početka i kraja štićene dionice. Takođe, prednost je selektivno isključenje kvarova bez potrebe pilotskih veza. Osnovni nedostatak je mala osjetljivost. Kod kratkog spoja na kraju štićenog voda ili u blizini sabirnica susjednog postrojenja razlika struja je suviše mala za djelovanje releja, tako da postoji određena mrtva zona. Zbog toga je potrebna dopunska zaštita i obično je to prekostrujna [2].

\section{ABB RED 615 - MIKROPROCESORSKI RELEJ}

ABB RED 615 je relej koji se koristi za zaštitu, upravljanje, mjerenje i nadzor $u$ distributivnim mrežama radijalne, prstenaste i mješovite strukture sa generatorima ili bez njih. Dizajniran je za rad u paru u svrhu korištenja podužne diferencijalne zaštite, s tim da ima sposobnost da radi mjerenja i proračune odvojeno za svaku fazu. RED 615 je je član ABB-ove porodice uređaja „Relion“ i dio njihove 615 serije za zaštitu i upravljanje [3]. Izgled releja dat je na slici 1 .

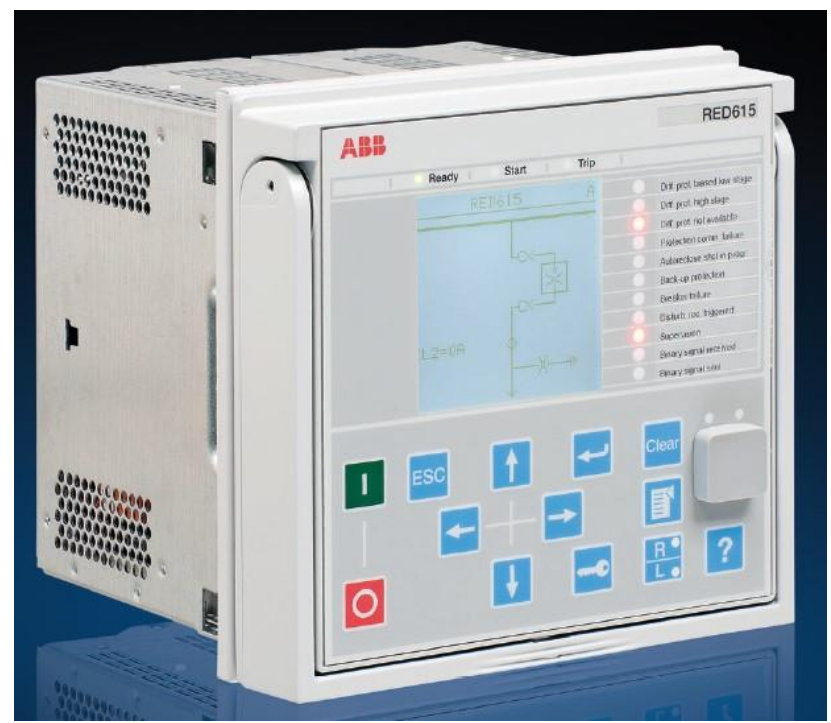

Slika 1. Izgled mikroprocesorskog releja RED 615

Releji sa dva kraja štićene zone komuniciraju između sebe preko optičkog kabla ili preko galvanizovanih pilot kablova. Ova 615 serija je karakteristična po svom kompaktnom i tzv. izvlačivom dizajnu. Rekonstruisana je ispočetka i vođena standardom IEC 61850 za komunikaciju tako da može da komunicira sa svom opremom $\mathrm{u}$ transformatorskoj stanici koja je dizajnirana po ovom IEC standardu [3]. Relej pruža glavnu zaštitu prenosnih vodova i visokonaponskih kablova u prenosnim i distributivnim mrežama. Takođe, posjeduje i prekostrujne zaštite koje se mogu kristiti kao rezervne zaštitne funkcije za lokalnu podužnu diferencijalnu zaštitu ili kao rezerva zaštitama koje su hijerarhijski ispod ovog releja u mreži.

Konfigurisanje releja, podešavanje zaštitnih funkcija, nadzor i upravljanje uređaja omogućava softver PCM600. Ovaj softver pruža veoma širok spektar podešenja vezanih za zaštitne i funkcije upravljanja uređaja odnosno releja u prenosnim i distributivnim mrežama.

U okviru softvera korisnik može da odradi veliki dio zadataka u oblastima planiranja, inženjeringa, testiranja i 
analize poremećaja koje uređaj zabilježi. Pomoću različitih alata moguće je obaviti određene zadatke u svrhu upravljanja cijelim objektom kao što je transformatorska stanica.

Relej ABB RED615 posjeduje sledeće zaštitne funkcije:

- $\quad L N P L D F$ - podužna diferencijalna zaštita;

- $\quad P H x P T O C$ - prekostrujna zaštita;

- $\quad N S P T O C$ - zaštita od nesimetričnog opterećenja;

- INRPHAR - detekcija udarne struje;

- $\quad$ CCBRBRF - zaštita od otkaza prekidača.

Funkcija podužne diferencijalne zaštite LNPLDF koristi se kao diferencijalna zaštita izvoda u distributivnim mrežama, bilo da su to vodovi ili kablovi [3]. Ova zaštitna funkcija sadrži dva stepena: niži stabilizovani i viši nestabilizovani. Podužna diferencijalna zaštita se takođe može koristiti i kada se u zoni štićena izvoda nalazi i transformator (slika 2).

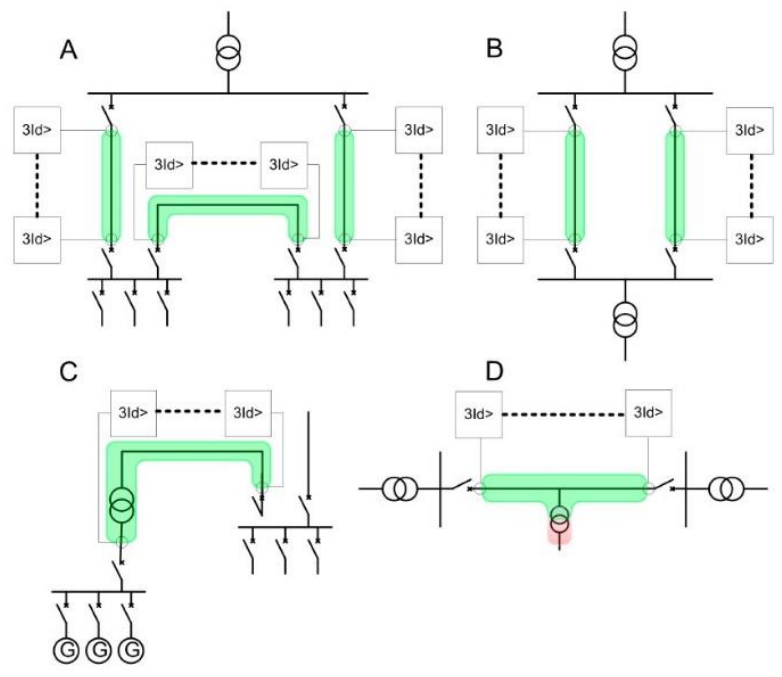

Slika 2. Primjene podužne diferencijalne zaštite

Trofazna prekostrujna zaštita pod nazivom PHxPTOC može se koristiti kao jednofazna, dvofazna ili trofazna neusmjerena prekostrujna zaštita i kao kratkospojna zaštita. Prorada funkcije se dešava $u$ trenutku prekoračenja vrijednosti struje iznad unaprijed podešene vrijednosti u okviru podešenja funkcije. Zaštita može biti aktivirana ili deaktivirana podešavanjem parametara $\mathrm{u}$ ovkiru kartice Operation u softveru PCM600. Princip rada neusmjerene prekostrujne zaštite ovog releja može se prikazati preko blok dijagrama na slici 3 .

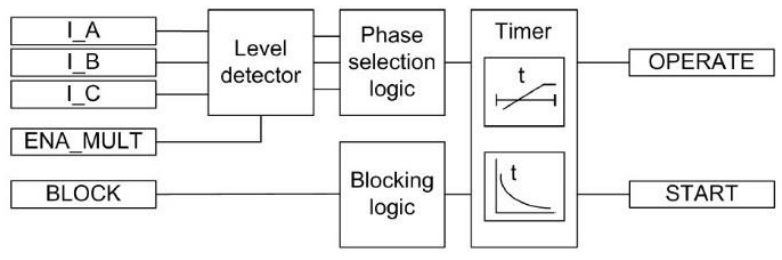

\section{Slika 3. Blok dijagram principa rada neusmjerene prekostrujne zaštite PHxPTOC}

Zaštita od nesimetričnog opterećenja NSPTOC koristi se za povećanje osjetljivosti pri detekciji jednofaznih ili međufaznih kvarova ili za detektovanje neuravnoteženog opterećenja usljed prekinutih provodnika i pojave nesi- metričnih napona. Rad funkcije se zasniva na mjerenju negativne komponente struje [3].

Detekcija tzv. udarne struje transformatora („INRPHAR“) koristi se za podešavanje prorade zaštite u situacijama pojave takvih struja u distributivnim mrežama. Prilikom uključivanja transformatora iz stanja mirovanja dolazi do javljanja udarne struje koja se manifestuje pojavom drugog harmonika polazne struje [3].

Funkcija CCBRBRF, odnosno zaštita od otkaza prekidača, aktivira se komandom za isključenje dobijenom od zaštitnih funkcija. Komanda može biti interna komanda prema terminalima ili komanda koja je stigla na binarne ulaze. Komanda početka rada je uvijek standardna za trofazan rad. Zaštita uključuje trofaznu uslovnu ili bezuslovnu funkciju kojom se šalje ponovljeni signal za isključenje (retrip), a takođe i trofaznu uslovnu rezervnu funkciju za isključenje (back-up-trip) [3].

\section{TESTIRANJE ZAŠTITNIH FUNKCIJA}

Ispitivanje i testiranje je izvršeno u laboratoriji firme „Albo Energy“ u Novom Sadu. Kako je na raspolaganju bio samo jedan uređaj RED615, a s obzirom na to da je za podužnu diferencijalnu zaštitu neophodno postojanje oba releja, jer rade u paru, nije bilo moguće odraditi testiranje ove zaštite. Međutim, ispitane su sve ostale zaštitne funkcije: PHIPTOC1, PHLPTOC1, PHHPTOC1, PHHPTOC2, NSPTOC1, NSPTOC2, a takođe ispitana je i funkcionalnost blokiranja rada funkcija.

Za testiranje je korišten ispitni alat proizvođača Omicron i to model CMC356. Ovaj uređaj je korišten za injekciju trofaznih struja, za praćenje izlaza releja koji signaliziraju pobudu i proradu zaštite i za slanje blokade funkcija na relej. CMC356 posjeduje određen broj analognih i digitalnih izlaza i ulaza, međutim za testiranje releja RED615 nisu bili neophodni svi ovi izlazi i ulazi,nego samo dio njih koji je prikazan na slici 4.

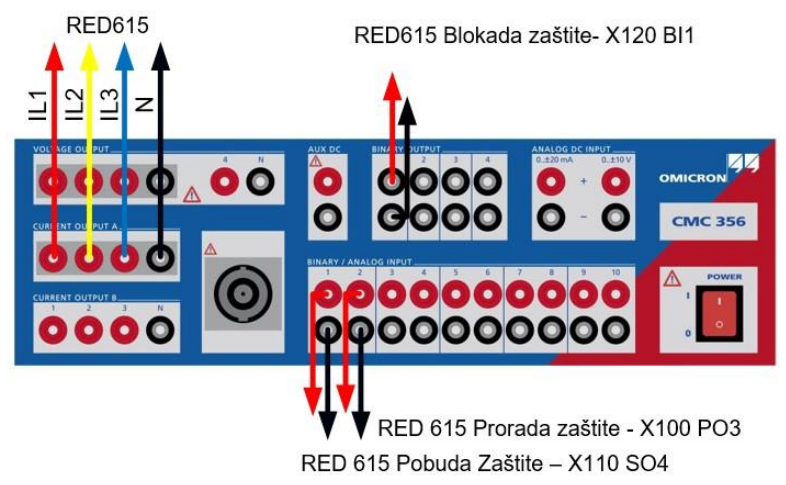

Slika 4. Povezivanje CMC356 sa relejom ABB RED 615

Da bi se moglo obaviti odgovarajuće testiranje sa ovim uređajem neophodno je i posjedovanje odgovarajućih licenci i softvera za testiranje. Programski paket koji se koristi je Omicron Test Universe.

U svrhu testiranja, bilo je neophodno ožičiti relej na odgovarajući test poligon, a potom ga povezati sa uređajem za testiranje. $\mathrm{Na}$ test poligonu prisutno je $\mathrm{AC}$ napajanje od $230 \mathrm{~V}$, sa zaštitnim automatskim prekidačem, koje obezbjeđuje izvor napajanja releju. S obzirom na to 
da su digitalni ulazi releja konstruisani za rad na $24 \mathrm{~V}$ prisutan je i AC/DC pretvarač od $24 \mathrm{~V}$.

Prilikom testiranja svih zaštitnih funkcija korištena su dva modula u softveru Test Universe i to: State Sequencer i Omicron test document - OCC. Takođe, u okviru OCC modula korišten je i modul Ramping prilikom određivanja vrijednosti pobuda zaštite. Razlog korištenja ova dva modula je da se pokaže da se testiranje može odraditi „ručno“ pomoću State Sequencer, gdje korisnik sve podešava samostalno, dok se kod OCC koriste odgovarajući test moduli tipični baš za vrstu zaštite koja se koristi. Npr. Overcurrent modul koristi se za sve prekostrujne zaštite.

Prilikom testiranja određene zaštitne funkcije neophodno je prvo podesiti odgovarajuće parametre. Na slici 5 prikazani su podešeni parametri zaštitne funkcije PHIPTOC.

\begin{tabular}{|c|c|c|c|c|c|}
\hline Group/Parameter Name & IED Value & PC Value & Unit & Min & Max \\
\hline \multicolumn{6}{|l|}{ PHIPTOC1: 1} \\
\hline $3 \mid>>>(1)$ & & & & & \\
\hline Operation & on & on & & & \\
\hline Num of start phases & & 1 out of 3 & & & \\
\hline Reset delay time & & 20 & ms & 0 & 60000 \\
\hline Setting Group 1 & & & & & \\
\hline Start value & 5.00 & 5.00 & $x \ln$ & 1.00 & 40.00 \\
\hline Start value Mult & & 1.0 & & 0.8 & 10.0 \\
\hline Operate delay time & & 50 & $\mathrm{~ms}$ & 20 & 200000 \\
\hline
\end{tabular}

Slika 5. Podešeni parametri zaštitne funkcije PHIPTOC

Za dobijanje režima kvara simuliran je tropolni kratak spoj i iščitani su zapisi o poremećajima iz releja (slike 6 i 7).
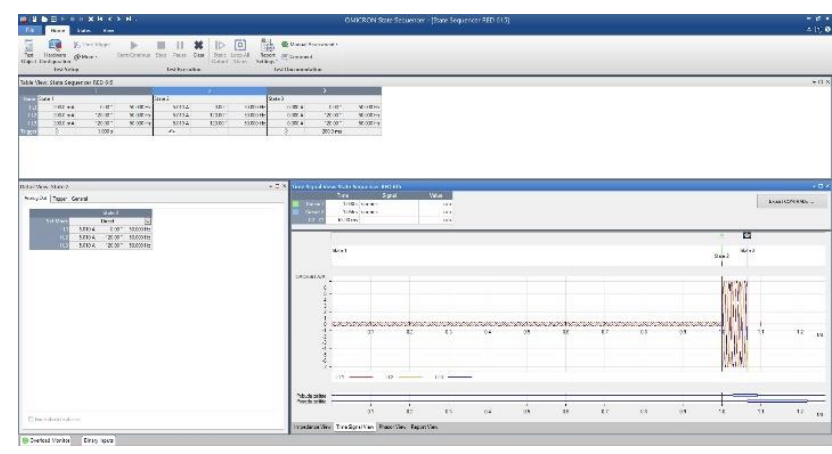

Slika 6. Simulacija tropolnog kratkog spoja

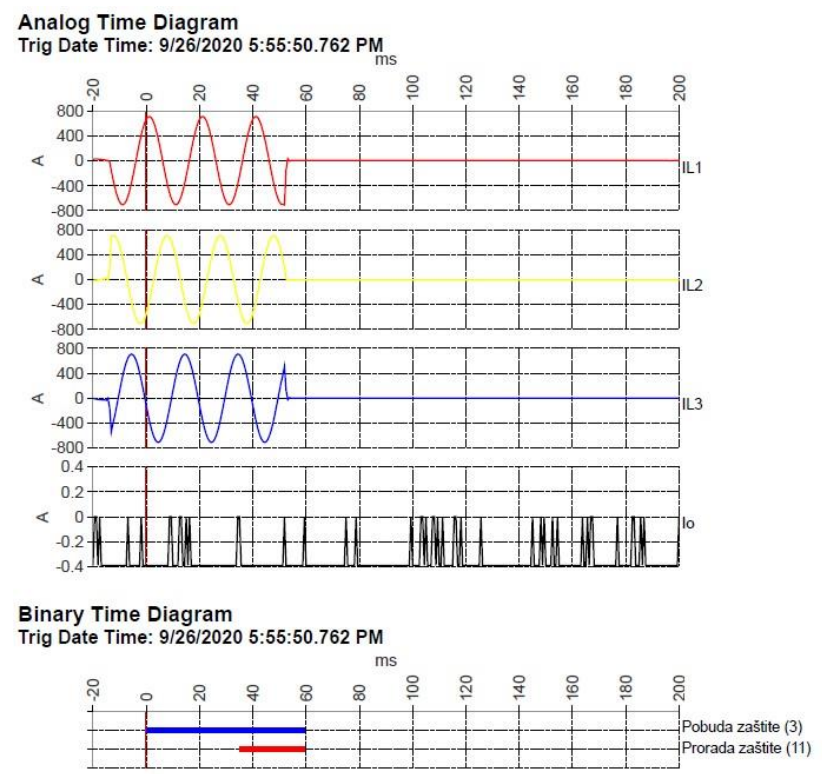

Slika 7. Zapis o poremećaju za 3pks u softveru PCM600
Sa dijagrama se može uočiti da se relej pobudio i proradio na pristutvo odgovarajuće struje kvara.

\section{ZAKLJUČAK}

Cilj ovog rada bio je da se odradi konfigurisanje mikroprocesorskog releja, a potom sprovedu određena testiranja. Da bi se to moglo realizovati, bilo je neophodno pružiti detaljan opis principa rada $\mathrm{i}$ funkcionisanja uređaja, odnosno njegovih zaštitnih funkcija. Nakon toga pristupilo se testiranju.

Da bi testovi bili što kvalitetniji, odnosno da bi se uređaj što bolje ispitao, rađeni su testovi na dva različita režima rada testnog alata i simulirane su situacije sa kvarom i to tropolni kratak spoj i dvopolni kratak spoj u različitim fazama.

Nakon svake simulacije kvara rađena je uporedna analiza podataka dobijena iz zapisa o poremećaju u releju sa povratnim informacijama koje su stizale na testni alat. Priloženim podacima o testiranju u dijelu rada „Testiranje zaštitnih funkcija“, može se zaključiti da su mjerene vrijednosti, kako struje kvara, tako i vremena pobude i prorade zaštite na oba mjesta skoro identične.

$\mathrm{S}$ obzirom na to da su sve dobijene vrijednosti $u$ referentnom opsegu i da su svi testovi zadovoljili odgovarajuće kriterijume, izvodi se zaključak da ovaj relej u potpunosti radi ispravno $\mathrm{i}$ da bi se $\mathrm{u}$ realnom pogonu ponašao baš onako kako se to od njega zahtijeva $i$ na taj način bi zaštitio element na koji je postavljen.

\section{LITERATURA}

[1] Duško Bekut, „Relejna zaštita“, Fakultet Tehničkih nauka, Novi Sad, 2009.

[2] Franjo Božuta, „Relejna zaštita“, Elektrotehnički fakultet, Sarajevo, 1991.

[3] ABB, „615 Series Technical Manual“, Product version: 5.0 FP1,2018.

\section{Kratka biografija:}

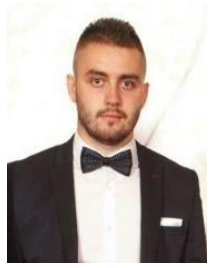

Milan Đurđević rođen je u Brčkom 1991. godine. 2013. godine je upisao Fakultet tehničih nauka, studijski program Energetika, elektronika i telekomunikacije. $\mathrm{Na}$ studijama se opredijelio za smjer Elektroenergetika - Elektroenergetski sistemi i diplomirao 2017. godine. Master studije upisao je 2017. godine.

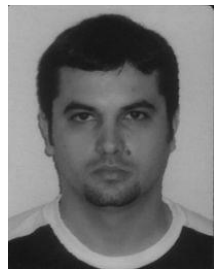

Zoran N. Stojanović rođen je 22.07.1979. godine u Požarevcu. Doktorsku disertaciju pod nazivom "Usmereni releji bazirani na digitalnom faznom komparatoru" odbranio je 11.06.2012. godine na Elektrotehničkom fakultetu Univerziteta u Beogradu. Oblasti naučnoistraživačkog rada kojima se do sada bavio su relejna zaštita, razvodna postrojenja i monitoring i dijagnostika visokonaponskih postrojenja. 